Tema: Solidificação / Ligotamento

\title{
UTILIZAÇÃO DE TAMPÃO FLUTUANTE NA PARTIDA DAS MÁQUINAS DE LINGOTAMENTO CONTÍNUO DE PLACAS DA ARCELORMITTAL TUBARAO*
}

\section{Resumo}

Alexandre Aparecida Morais ${ }^{1}$ Jose Carlos de Pontes Junior ${ }^{2}$ Sandro de Souza Santos ${ }^{3}$ Marcelo Rodrigues de Andrade ${ }^{4}$ Eder de Souza Silva ${ }^{5}$ Euclésio Mognato 6

No processo de lingotamento contínuo de placas, o controle de fluxo de aço líquido entre o distribuidor e os moldes pode ser realizado através de tampão refratário ou válvula gaveta. Quando se usa o controle via tampão refratário, aproveita-se o mesmo para reter um volume mínimo de aço no distribuidor, visando efetuar a partida do veio. Este volume de aço é importante para evitar o congelamento da primeira porção de aço e prevenir o arraste de impurezas existentes no fundo do distribuidor para o molde. Já quando se usa o controle via válvula gaveta, para acumular o volume de aço necessário, utiliza-se de outros "artifícios", como o uso de anteparos metálicos em forma de bujões, cuja eficiência é limitada. Visando melhorar o desempenho de partida das máquinas com controle de fluxo de aço distribuidor-molde, via válvula gaveta, desenvolveu-se o chamado tampão flutuante de fibra cerâmica, cujas funções principais são: equalizar o nível de aço para proporcionar uma partida normal e impedir que impurezas arrastadas pela primeira porção de aço, se dirijam para os veios. Este trabalho mostra o desenvolvimento pioneiro desta técnica para distribuidores de aços planos na ArcelorMittal Tubarão.

Palavras-chave: Distribuidor; Tampão refratário e flutuante.

\section{DEVELOPMENT OF FLOATING STOPPER IN THE TUNDISH OF CONTINUOUS CASTING MACHINES AT ARCELORMITTAL TUBARÃO}

\begin{abstract}
In continuous casting of slabs, steel flow from tundish to mold is usually controlled by stopper rod system or slide gate nozzle. When the flow control is performed via stopper rod, a minimum amount of steel is required to start filling the mold. This volume of steel is important to avoid starting cast freezing, as well as to promote flotation of impurities come with the first stream of steel, or rest in the tundish floor. However, when the steel flow is controlled via the slide gate nozzle, it is necessary to use devices like metallic stoppers in the form of plugs, which have limited efficiency. Aiming to improve the starting performance of continuous casting machines that use steel flow control tundish-mold via the slide gate nozzle, it was developed the so-called floating ceramic fiber stopper, whose main functions are to equalize the level of steel to provide a normal cast starting and prevent impurities which are entrained by the first stream of steel. Initially used for billets, it was developed and deployed in the continuous casting slabs at ArcelorMittal Tubarão. This paper shows the pioneering of the development and the gains from the implementation of this device.

Key words: Tundish; Refractory stopper; Floating ceramic fiber stopper.

Mestre em Metalurgia e Engenharia de Materiais, Físico, Especialista em Lingotamento Contínuo, ArcelorMittal Tubarão, Membro da ABM, Vitória, ES, Brasil.

2 Engenheiro Metalúrgico, Gerente da Área de Confiabilidade de Produção de Placas, ArcelorMittal Tubarão, Serra, ES, Brasil.

3 Mestre em Engenharia de Materiais, Engenheiro Metalúrgico, Gerente, ArcelorMittal Tubarão, Serra, ES, Brasil.

4 Técnico Mecânico, Reframax, Serra, ES, Brasil.

5 Engenheiro Metalúrgico, Gerente Executivo, Thermes, Serra, ES, Brasil.

6 Engenheiro de Produção, Supervisor Lingotamento Contínuo, ArcelorMittal Tubarão, Serra, ES, Brasil.
\end{abstract}

* Contribuição técnica ao $45^{\circ}$ Seminário de Aciaria - Internacional, 25 a 28 de maio de 2014, Porto Alegre, RS, Brasil. 


\section{INTRODUÇÃO}

Ao longo do desenvolvimento do lingotamento contínuo de aços verificou-se que garantir uma porção de aço mínima no distribuidor para equalização da partida dos veios é de fundamental importância. Tal procedimento, conforme descreve Morais [1] "evita dentre outras anormalidades o congelamento de aço na partida (pressão ferrostática) e impede o arraste de resíduos de material refratário e outras impurezas exógenas que podem estar presentes na sola do distribuidor, antes do seu enchimento". A obtenção ou retenção deste nível mínimo de aço no distribuidor é conseguido de diferentes formas, sendo as mais usuais através de dispositivos refratários ou metálicos. Quando se efetua o controle do fluxo de aço do distribuidor para o molde via tampão refratário, utiliza-se este próprio dispositivo para promover esta reserva de aço; já quando se usa o mecanismo de válvula gaveta para controle de fluxo, utilizam-se geralmente bujões metálicos, luvas refratárias, para elevação do nível de aço no distribuidor para a partida. Todavia, estes dispositivos metálicos e refratários não são plenamente eficientes e chegam a comprometer as partidas, provocando, por exemplo, a obstrução do fluxo de aço. Na busca de uma tecnologia que atue com melhor desempenho neste quesito nas partidas de máquina as Indústrias do Aço e de Refratários vem procurando alternativas, desde a melhoria da mobília interna dos distribuidores (dispersores, diques, barragens, luvas cerâmicas, etc.) ao desenvolvimento de novas tecnologias. Dentro desse contexto, desenvolveu-se o tampão de fibra cerâmica, com capacidade para formar uma coluna de aço adequada aos propósitos já descritos acima. Contudo, este desenvolvimento, em função dos temores quanto à resistência a grandes volumes de aço, restringiu-se, inicialmente, somente aos distribuidores de pequeno porte utilizados nas indústrias de aços longos.

No Brasil, esta tendência persistiu até meados de 2008 quando se iniciou nos distribuidores de grande porte (capacidade $>50$ toneladas de aço) da Siderúrgica de Tubarão um trabalho pioneiro em conjunto com a Indústria de Fibra Cerâmica, no desenvolvimento de um tampão cerâmico adaptado às condições de processo da indústria de aços planos do porte de Tubarão, cujo fluxo de aço distribuidor-molde é efetuado pelo sistema de válvula gaveta. O trabalho pautou-se em um elaborado Plano Experimental, metodologicamente definido para os diferentes aspectos do processo, considerando alguns conceitos básicos do mecanismo de desgaste de refratário e fibra cerâmica, conforme estudos de Callister [2] e foi avaliado, criteriosamente, através de análises de viabilidade técnica-operacional, qualitativa e econômica de cada etapa.

O tampão de fibra cerâmica definido para o projeto, possui o dimensionamento embasado nos fundamentos do fluxo de aço, teorizados por Duff [3], que são melhor explorados no capítulo 2 (Material e Métodos). Estes são produzidos por processo de moldagem a vácuo, onde uma pasta composta por fibra cerâmica Fiberfrax ${ }^{\circledR}$ (Figura 1) e ligantes especiais para alta temperatura é aspirada ao molde pela ação do vácuo, assumindo um formato tubular de alta resistência.

* Contribuição técnica ao 450 Seminário de Aciaria - Internacional, 25 a 28 de maio de 2014, 


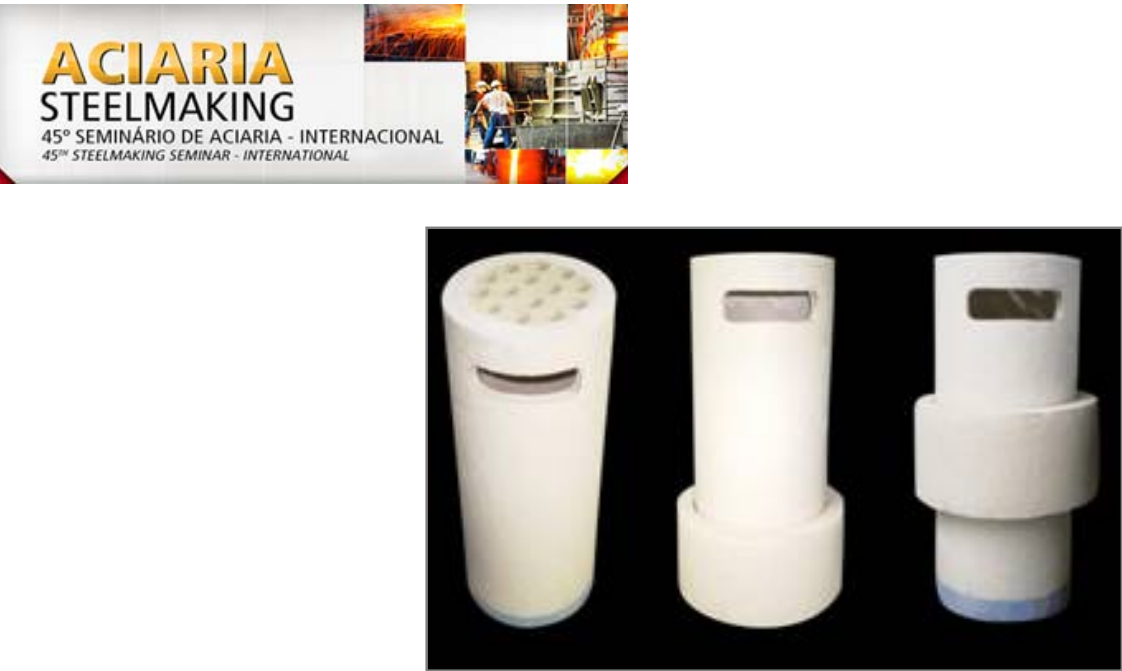

Fonte: Fornecedor do Tampão Moldafrax RK - Fiberfrax ${ }^{\circledR}$

Figura 1. Ilustração do Tampão Cerâmico Flutuante.

As principais características físico-químicas dos tampões cerâmicos são demonstradas na Tabela 1.

Tabela 1. Características físico-químicas dos tampões cerâmicos

\begin{tabular}{|c|c|}
\hline \multirow{4}{*}{$\begin{array}{l}\text { PROPRIEDADES } \\
\text { QUIIMICAS }\end{array}$} & $\begin{array}{l}\text { Resistem ao ataque dos agentes corrosivos, com exceção dos } \\
\text { ácidos fluorídrico e fosfórico e os álcalis concentrados. }\end{array}$ \\
\hline & Resistencia à oxidação e redução. \\
\hline & Sem água na composição química. \\
\hline & $\begin{array}{l}\text { Se receberem água, vapor ou óleo, as propriedades térmicas e } \\
\text { físicas são completamente restauradas com a secagem. }\end{array}$ \\
\hline \multirow{7}{*}{$\begin{array}{l}\text { PROPRIEDADES } \\
\text { FÍSICAS TÍPICAS }\end{array}$} & Cor branca ou amarelo claro \\
\hline & Composição básica: alumina sílica \\
\hline & Temperatura de trabalho: $1600^{\circ} \mathrm{C}$ \\
\hline & Ponto de fusão: $1816^{\circ} \mathrm{C}$ \\
\hline & Densidade: 190 a $800 \mathrm{~kg} / \mathrm{m}^{3}$ \\
\hline & Calor específico a $1100^{\circ} \mathrm{C}: 1130 \mathrm{~J} / \mathrm{kg}^{\circ} \mathrm{C}$ \\
\hline & Faixa de espessura: 6 a 300mm \\
\hline \multirow{5}{*}{ OUTRAS } & Estabilidade em alta temperatura $\left(>1100^{\circ} \mathrm{C}\right)$ \\
\hline & Baixa condutividade térmica: $<0,02 \mathrm{~W} /(\mathrm{m} \cdot \mathrm{K})$ \\
\hline & Resistência ao choque térmico \\
\hline & Excelente resiliência \\
\hline & Excelente flexibilidade \\
\hline
\end{tabular}

Fonte: Unifrax - Brasil

\subsection{Objetivo}

O principal objetivo do trabalho é mostrar os principais pontos do desenvolvimento do tampão de fibra cerâmica nos distribuidores de lingotamento contínuo de Tubarão, bem como os resultados com a sua implantação.

\subsection{Revisão da Literatura}

Conforme já comentado, na partida do lingotamento, para que ocorra o correto fluxo de aço do distribuidor para o molde controlado pelo sistema de válvula gaveta, fazse necessário uma coluna metalostática que possui dupla finalidade: flotar as impurezas exógenas presentes no refratário do distribuidor e exercer uma pressão sobre o canal de alimentação distribuidor-molde que evite o congelamento do aço, descrito pelos pesquisadores Garcia [4], Kurz e Fisher [5] que o atribui a uma história térmica, pela qual o calor é transferido e ocorre a distribuição de temperatura no interior do distribuidor para o molde. É neste ambiente onde a cada instante em

* Contribuição técnica ao 45 Seminário de Aciaria - Internacional, 25 a 28 de maio de 2014, 
regime transiente tem-se a remoção de calor em sua forma latente, que se posiciona o tampão de fibra cerâmica sobre o orifício de alimentação distribuidormolde. Para enfrentar a agressividade deste meio adotou-se na especificação do tampão os conceitos de resistência da fibra cerâmica difundidos por Lanik [6], em função das pesquisas de filtragem de aço, através de peças de fibra cerâmica.

\section{MATERIAL E MÉTODOS}

O trabalho experimental, porém, fundamentado na filosofia "Seis Sigma de Werkema" [7], iniciou com a caracterização do problema-oportunidade, passando por todas as fases desta metodologia.

A partir da especificação do tampão cerâmico flutuante, através de discussões com o fornecedor da fibra cerâmica do tampão Moldafrax RK (Fiberfrax ${ }^{\circledR}$ ), elaborou-se um Plano de Experiência para os testes na área. O embasamento destes, bem como às análises previstas, apoiaram-se nos estudos de fluxo e simulação sobre o escoamento de aço no distribuidor realizados por Duff [3] e Thomas [8], e nas experiências de Morais [1] relativas à obstrução no início de lingotamento.

\subsection{Especificações do Tampão de Fibra Cerâmica}

- Componentes: tubo (luva) cerâmica com uma das extremidades vedada com 14 pequenos orifícios e anel cerâmico flutuante;

- $\quad$ capacidade do distribuidor = 60t;

- volume de aço retido desejado para a partida (mínimo de 10t, máximo de 25t);

- vazão do aço do distribuidor para o molde (faixa 14,0 a 16,0t/min);

- densidade do tampão: $780 \mathrm{~kg} / \mathrm{m}^{3}$.

A partir destas referencias estabeleceu-se as dimensões do tampão: diâmetro de $250 \mathrm{~mm}$, espessura de $40 \mathrm{~mm}$ e altura de $600 \mathrm{~mm}$.

\subsection{Princípio de Funcionamento}

O tampão de fibra cerâmica posicionada dentro do distribuidor funciona conforme o esquema descrito a seguir e ilustrado conforme a Figura 2 abaixo.

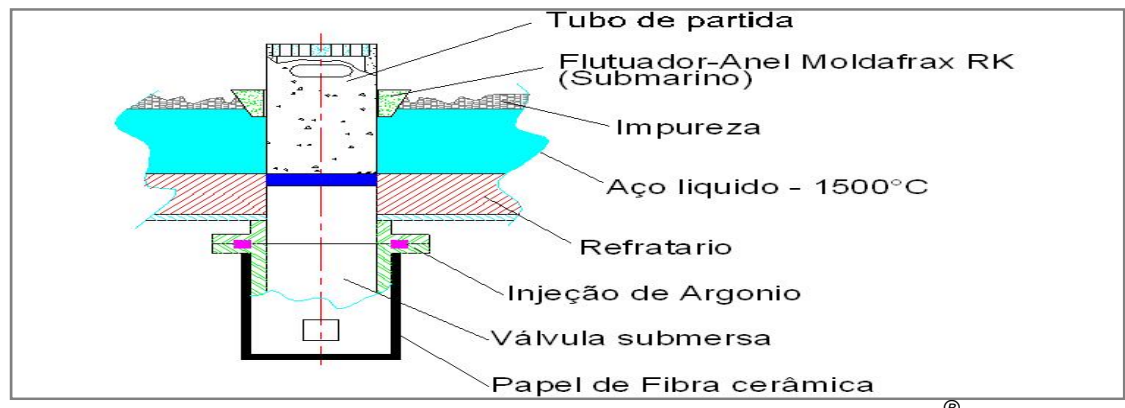

Fonte: Fornecedor do Tampão Moldrafax RK - Fiberfrax ${ }^{\circledR}$

Figura 2. Esquema Básico de Funcionamento Tampão Flutuante.

A flutuação do tampão de fibra cerâmica objetivando a equalização do nível de aço e a flotação de impurezas indesejáveis ocorre em função da menor densidade deste em relação ao aço. A primeira porção de aço que alimenta o distribuidor arrasta consigo impurezas de refratários e outras. Utilizando o tampão flutuante (esquematizado nas Figuras 2 e 3) quando esta primeira porção de aço com as

* Contribuição técnica ao 45 Seminário de Aciaria - Internacional, 25 a 28 de maio de 2014, 


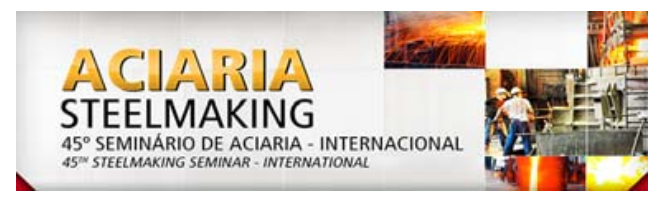

impurezas existentes chegam ao orifício de alimentação distribuidor-molde (boca da válvula superior) encontra a barreira do tubo com o flutuador-anel (Moldafrax $\mathrm{RK}^{\circledR}$ ). Este então vai se elevando à medida que o distribuidor vai enchendo de aço e ao chegar ao orifício de alimentação na parte superior do tubo não deixa que as impurezas penetrem no canal de alimentação do molde. Além disso, forma-se um nível de aço (coluna de aço) que aumenta a garantia da alimentação inicial do molde, pela pressão metalostática.

Quando a coluna de aço ultrapassa a altura do bocal do tampão cerâmico flutuante e a temperatura no interior do tampão se equaliza com a temperatura do exterior do mesmo, este sofre uma espécie de contração desprendendo e flutuando totalmente até a superfície do banho metálico do distribuidor; decompondo-se ao longo do tempo de lingotamento pelo ataque da escória. A Figura 3 abaixo explicita melhor o esquema de funcionamento.

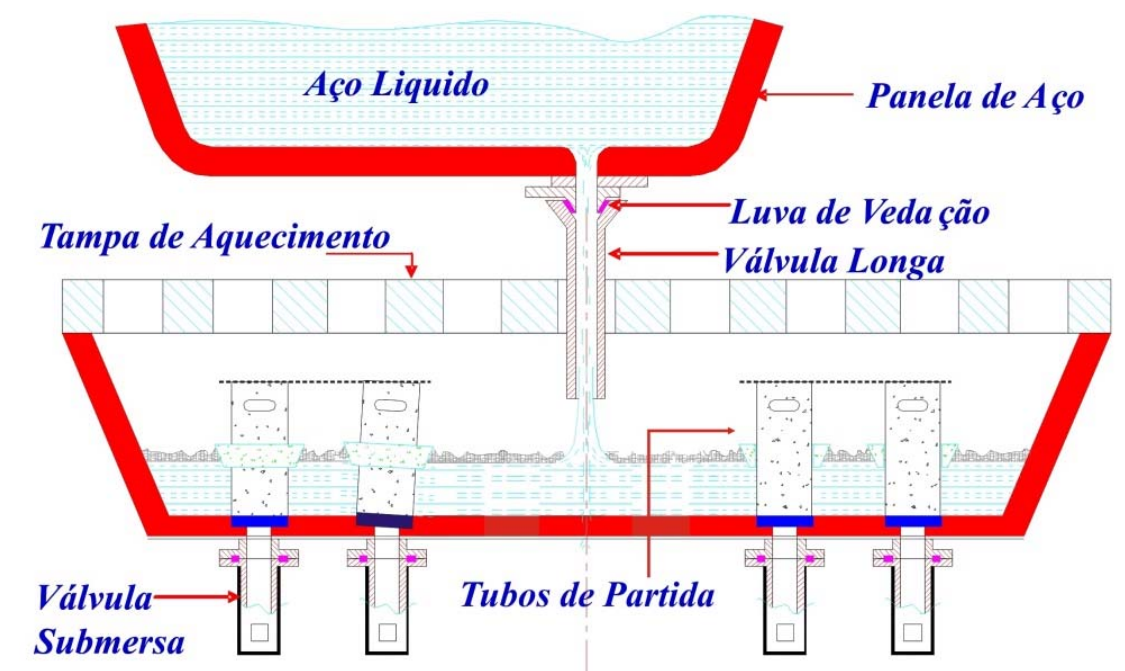

Fonte: ArcelorMittal Tubarão e Fornecedor do Tampão Moldrafax RK - Fiberfrax ${ }^{\circledR}$

Figura 3. Esquema Básico de Funcionamento Tampão Flutuante em Veios tipo "twin".

\subsection{Fase Experimental}

A experiência realizada na Área de Lingotamento Contínuo da ArcelorMittal Tubarão (Máquinas 1, 2 e 3) iniciou em escala piloto e progrediu para escala industrial sem restrições em um período de trinta e seis meses.

$\mathrm{Na}$ primeira etapa física da experiência definiu-se para os testes condições de contorno que contemplavam um único veio de lingotamento, tipos de aços específicos, o tipo de partida (a quente ou a frio). Estas restrições no decorrer do Plano de Experiência foram sendo retiradas, em virtude das análises dos resultados. Ainda nesta etapa as condições de controle foram estabelecidas, definindo-se como parâmetros e variáveis de análises a serem validadas: a resistência do tampão à temperatura de pré-aquecimento do distribuidor, a resistência ao impacto do aço, a tonelagem de aço retida no distribuidor antes da partida, a eficiência na partida, a qualidade nas primeiras e últimas placas e a influencia na sobra de aço no distribuidor ao final do sequencial.

Outro aspecto importante nesta fase foram os procedimentos estabelecidos para a realização da montagem do tampão no distribuidor, onde se contemplou, dentre outros, os aspectos operacionais e de segurança, a profundidade de fixação, argamassa de fixação, o plano de nivelamento, o deslocamento da luva flutuante, a

* Contribuição técnica ao $45^{\circ}$ Seminário de Aciaria - Internacional, 25 a 28 de maio de 2014, Porto Alegre, RS, Brasil. 
secagem vertical e horizontal, a secagem do conjunto e outros. As Figuras 4 e 5 ilustram a montagem do tampão e luva dentro do distribuidor.

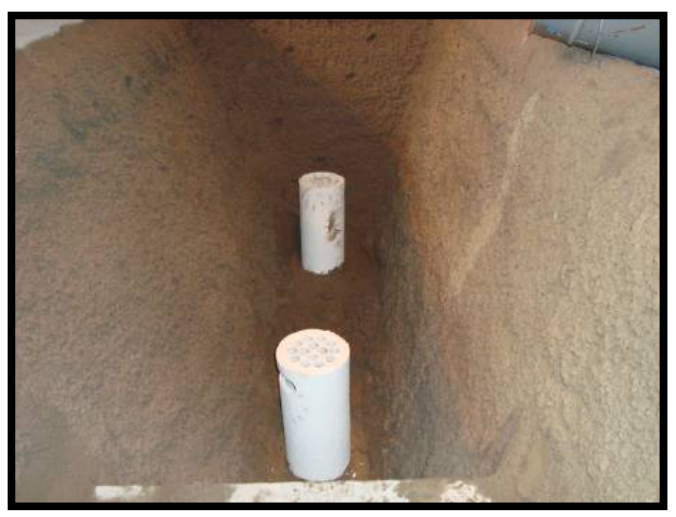

Figura 4. Tampão montado sem a luva.

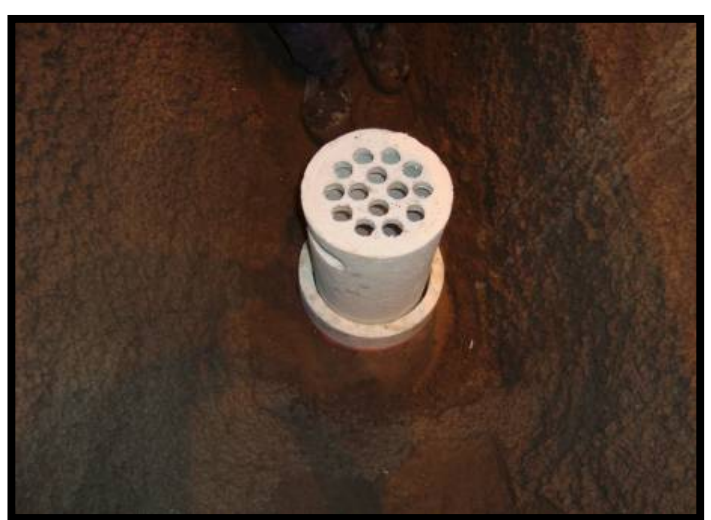

Figura 5. Tampão montado com a luva.

Ainda na fase de elaboração do Plano Experimental com base nas condições de controle determinadas acima, definiu-se também os parâmetros e variáveis para análise da viabilidade econômica.

Com o avanço dos testes e a obtenção dos dados coletados, efetuaram-se as análises previstas (ver descrição acima), cujos resultados são mostrados.

\section{RESULTADOS}

Após a realização de mais de 230 partidas usando o tampão cerâmico flutuante, foram obtidos resultados bastante promissores em todos os parâmetros e variáveis de controle pré-estabelecidos. Estes são apresentados a seguir.

\subsection{Resistência do Tampão da Temperatura de Pré-Aquecimento do Distribuidor}

Avaliou-se a resistência tanto em distribuidores de partida frio (usados após secagem - umidade $<0,5 \%$ ), quanto distribuidores de partida a quente (realização de secagem e o pré-aquecimento - temperatura superficial $>1000^{\circ} \mathrm{C}$ ). Não se detectou qualquer tipo de deterioração do tampão.

Nos distribuidores a quente o mesmo resistiu, sem deformação, ao padrão máximo de pré-aquecimento, onde se atingiu temperaturas superficiais de $1200^{\circ} \mathrm{C}$.

Nos distribuidores a frio quando o mesmo trabalha também como defletor (anteparo) para pré-aquecimento do canal de alimentação do distribuidor-molde (aquecimento pela válvula submersa), o mesmo melhorou a temperatura do canal, atingindo valores superiores aos usuais (quando se utiliza defletores metálicos ou refratários).

A Figura 6 abaixo mostra um gráfico representando uma amostragem de aquecimentos comparando os valores de temperatura de canal obtidos usando o tampão e os defletores metálicos e refratários. Os valores "A20, A8"..., significam o número de amostragens que apresentaram similaridade de valores térmicos usando as mesmas premissas (padrão de aço, unidade de refino, etc.); evidentemente, na condição de partida a quente e a frio separadamente. Exemplo: Na amostragem com a simbologia "A20" significa 20 (vinte) condições de partida com tampão flutuante com valores similares e 20 (vinte) condições de partida com outro tipo de artificio com valores similares (exemplo: metálico ou refratário). O somatório dessas amostragens dá um montante de 179 amostragens para cada tipo de partida.

* Contribuição técnica ao 45 Seminário de Aciaria - Internacional, 25 a 28 de maio de 2014, Porto Alegre, RS, Brasil. 
Verifica-se que, em média, quando se utilizou o tampão flutuante, o canal de alimentação distribuidor-molde ficou mais quente em aproximadamente $70^{\circ} \mathrm{C}$ acima dos valores obtidos com outros artifícios, metálicos ou refratários.

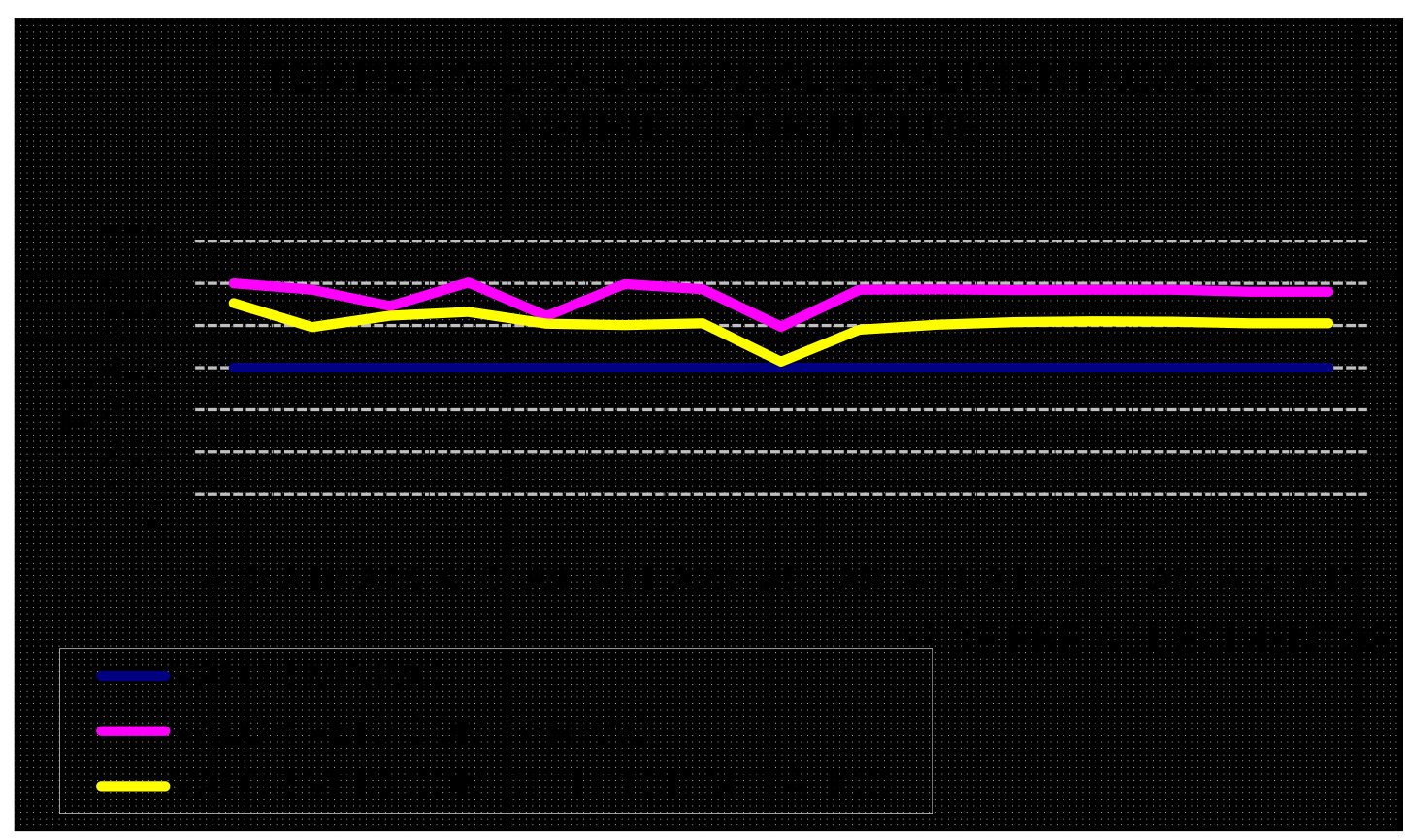

Figura 6. Evolução Temperatura em ${ }^{\circ} \mathrm{C}$ do Canal Distribuidor-Molde.

\subsection{Resistência ao Impacto do Aço e Eficiência na Partida}

Mesmo com vazões de aço da panela para o distribuidor de até 16t/min, não ocorreu deformação do tampão. Também no caso de inclinação da válvula longa ou ocorrência de jato exposto (lingotamento sem válvula longa), o tampão resistiu e funcionou conforme previsto, ou seja, o deslizamento da luva e a flutuação do tampão ocorreram nos momentos esperados.

Em nenhuma das partidas ocorreu desprendimento prematuro do tampão, devido à má fixação ou não resistência ao impacto da primeira porção de aço.

\subsection{Tonelagem de Aço Retida no Distribuidor Antes da Partida}

Os valores obtidos atingiram a faixa padrão desejada. No gráfico demonstrado na Figura 7 verifica-se que não houve retenção de aço no distribuidor antes da partida fora dos limites inferiores e superiores do padrão de referencia.

* Contribuição técnica ao 45 Seminário de Aciaria - Internacional, 25 a 28 de maio de 2014, 


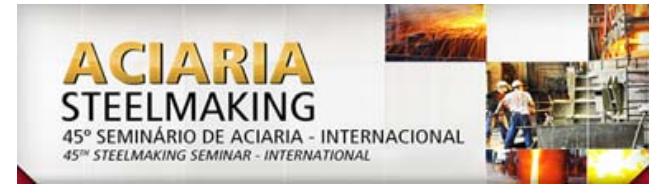

\section{TONELAGEM DE AÇO RETIDA ANTES DA PARTIDA}

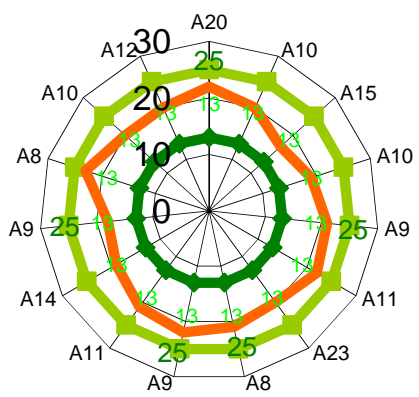

-TONELAGEM MÍNIMA REFERENCIA (13T)

-TONELAGEM MÁXIMA REFERENCIA (25T) TONELAGEM RETIDA - 130 AMOSTRAS

Figura 7. Demonstração da tonelagem retida para a partida do veio usando o tampão.

\subsection{Qualidade nas Primeiras e Últimas Placas Produzidas}

Os resultados de qualidade, comparados na mesma base (tipo de aço, condições de enchimento do distribuidor e partida de lingotamento), avaliaram nas primeiras e últimas placas, os defeitos superficiais e subsuperficiais (inclusões e bolhas).

$\mathrm{Na}$ avaliação das últimas placas foram encontrados resultados semelhantes, já nas primeiras placas houve uma redução de $27 \%$ das inclusões a favor do tampão flutuante. Atribui-se este resultado a capacidade de flotação das inclusões em função do tampão cerâmico funcionar efetivamente como uma barreira fixa contra o arraste das impurezas. O Gráfico da Figura 8 mostra a detecção dos defeitos "bolhas e inclusões" no "check de escarfagem".

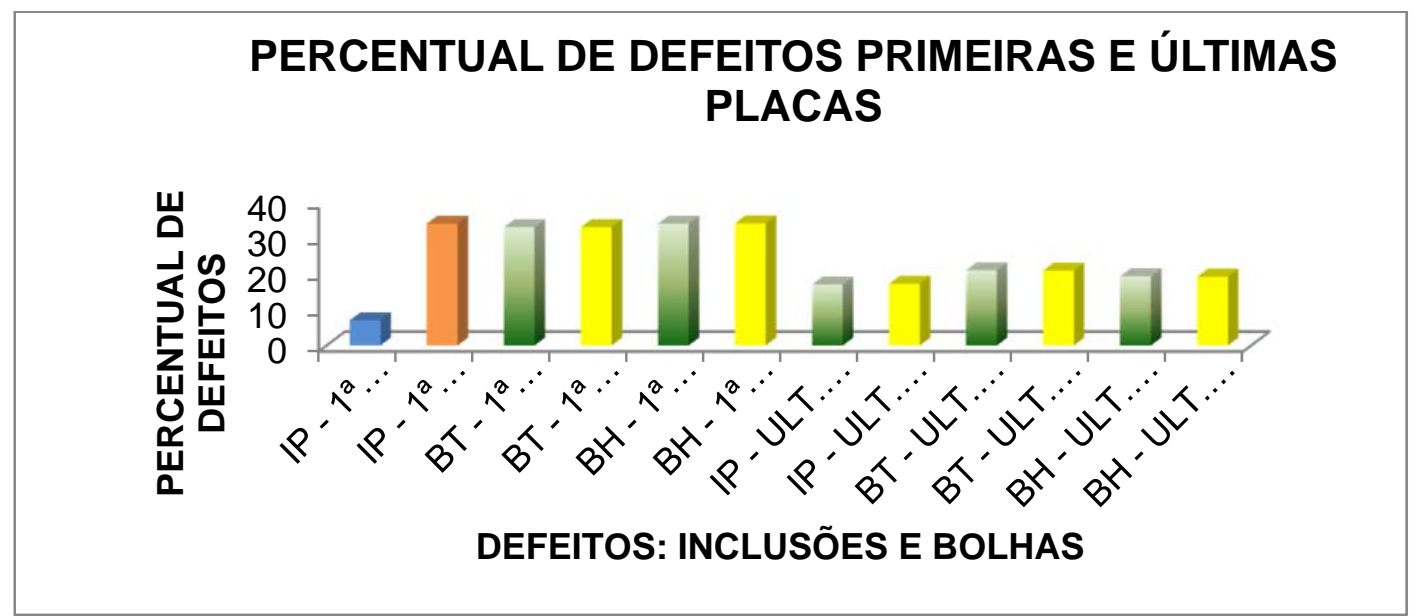

Figura 8. Percentual detectado de inclusões e bolhas nas primeiras e últimas placas.

\subsection{Sobra de Aço no Distribuidor}

Ao iniciar a experiência esperava-se uma maior sobra de aço utilizando o tampão cerâmico em função do mesmo flutuar para a escória durante o lingotamento, não permanecendo como barreira no final do lingotamento. Todavia, não se detectou esta perda (gráfico da Figura 9). Acredita-se que a semelhança de resultados de

* Contribuição técnica ao $45^{\circ}$ Seminário de Aciaria - Internacional, 25 a 28 de maio de 2014, 


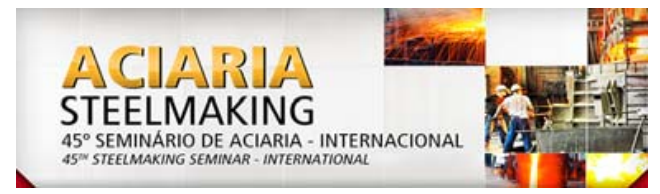

sobra de aço entre o tampão cerâmico flutuante e o refratário deve-se às condições de processo (passagem de escória panela-distribuidor). A sobra média de aço foi equivalente a 7 toneladas, para ambas as condições.

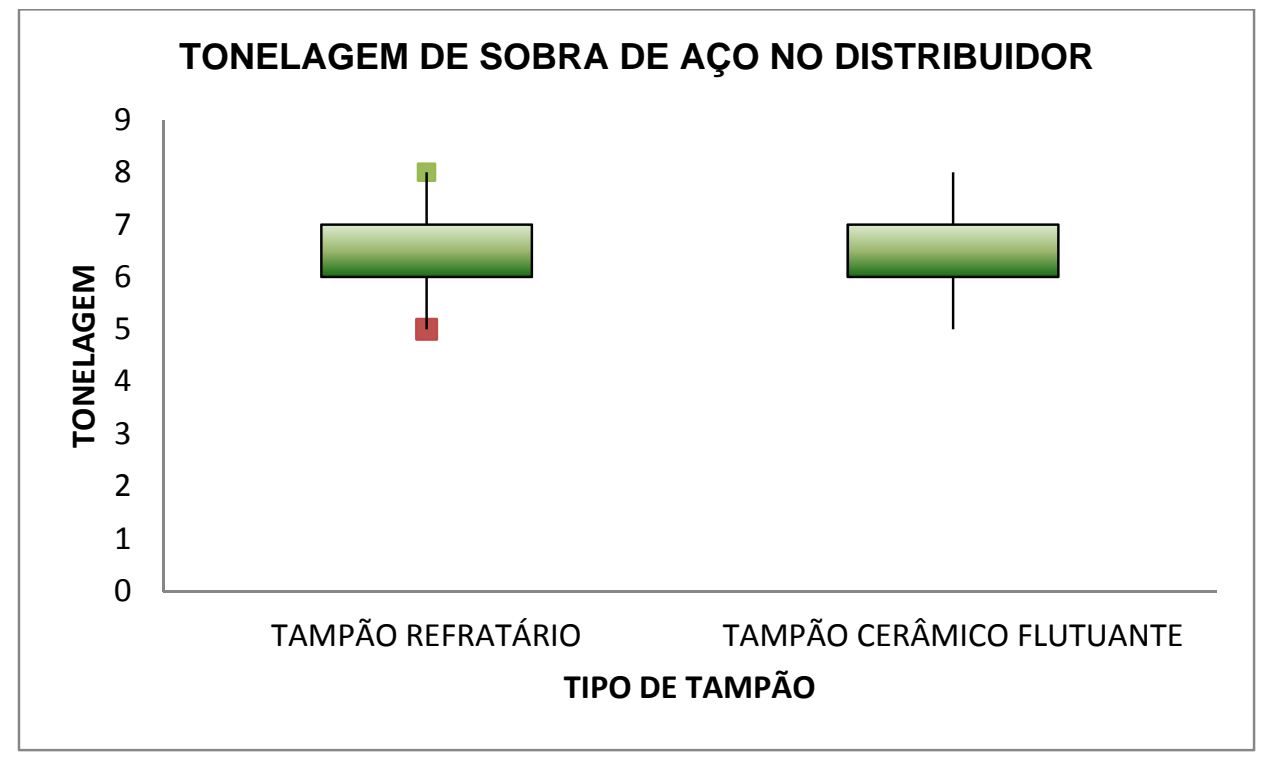

Figura 9. Sobra de Aço no Distribuidor.

\subsection{Viabilidade Econômica}

A comparação entre os valores de custo entre o tampão refratário usual e o tampão cerâmico flutuante, mostra que o valor da unidade do flutuante é aproximadamente $393 \%$ menor que a unidade do refratário usual. Esta economia só computou o custo da peça, ou seja, não computou os gastos com a manutenção do sistema de acionamento do tampão refratário usual, que no caso de Tubarão é hidráulico. A redução de custo dentro de uma produção estimada de 2,3 milhões de toneladas de placas, considerando somente a substituição da peça refratária é de aproximadamente 1,1 milhão de dólares por ano.

\section{DISCUSSÃO}

Os estudos e os resultados apresentados sobre a possibilidade de utilização de tampão cerâmico flutuante em distribuidores de grande capacidade para produção de placas no processo Contínuo sinalizaram uma favorabilidade importante para a utilização deste em sistemas onde o controle de fluxo do aço líquido é realizado por válvula gaveta e o uso do tampão refratário se restringe à necessidade de retenção de aço para a partida do veio.

A metodologia experimental empregada se mostrou consistente, ao definir previamente o escopo de testes partindo de um veio e posteriormente generalizando, e sempre mantendo os pressupostos de comparação definidos, ou seja, a viabilidade técnica-operacional, qualitativa e econômica.

Verificou-se que na parte técnica-operacional não houve incrementos de manuseio, já que as tarefas de fixação do tampão flutuante na preparação do distribuidor substituíram as tarefas de montagem e ligações hidráulicas do tampão refratário. No aspecto operacional ainda pode-se explorar o ganho de segurança humana (redução da exposição ao calor e altura) quando se evita a colocação do anteparo para pré-aquecimento e bujão metálico que é um dos artifícios utilizados quando não

* Contribuição técnica ao $45^{\circ}$ Seminário de Aciaria - Internacional, 25 a 28 de maio de 2014, Porto Alegre, RS, Brasil. 
se usa o tampão refratário. Também dentro do escopo operacional a utilização do tampão cerâmico flutuante abre a possibilidade de realização de desobstrução com oxigênio desde que tomadas às devidas medidas de segurança padronizadas. Tecnicamente não se observou dificuldades ou limitações para a utilização do tampão flutuante. A sua resistência, a sua praticidade merecem destaque. Um aspecto técnico significativo foi a constatação da sua eficiência como anteparo para facilitar o pré-aquecimento do canal de alimentação distribuidor-molde, onde se pode verificar um ganho térmico com a utilização deste. Este ganho térmico da ordem de $70^{\circ} \mathrm{C}$ pode significar uma melhor condição de partida.

Um derradeiro aspecto tecnológico que deve ser mencionado é relativo às pequenas alterações de parâmetros de partida (relativos ao controle eletroeletrônico) que foram necessárias para garantir a adequação do enchimento do molde ao novo sistema. Basicamente, restringiram-se às rotinas que eram pertinentes ao programa do sistema de tampão refratário que se utilizava.

A checagem dos parâmetros de qualidade fixados nas primeiras e últimas placas, também mostrou resultados similares e no caso das inclusões nas primeiras placas, o resultado do tampão flutuante foi melhor que o refratário. Contudo, esperava-se que nas últimas placas os resultados com tampão refratário fossem melhores, pois, o mesmo possui a característica de poder quebrar o vortex do fluxo de aço distribuidor-molde. Analisando esta condição pode-se especular que talvez a altura que se mantem o tampão refratário após a partida do veio, não seja adequada para tal impedimento do vortex, o que então torna os resultados entre os tampões similares. Tal condição pode explicar também o motivo das sobras de aço idênticas para as duas condições. As análises destas condições podem ser aprofundadas em estudos posteriores, para encontrar pontos de maior efetividade do tampão refratário. Todavia, mesmo se este reduzisse em 100\% a sobra de aço em relação ao flutuante, o peso econômico ainda seria mais favorável ao flutuante.

Já a viabilidade econômica do flutuante foi bastante atraente, pois, sem considerar o custo de manutenção do sistema hidráulico do tampão refratário, só se comparando as peças unitárias, o custo do tampão flutuante é 393\% menor.

Em termos comparativos com os resultados de outras plantas o trabalho deixa uma lacuna; e esta ocorre, devido ao fato do pioneirismo desse desenvolvimento em Tubarão (siderúrgica de produtos planos, que utiliza distribuidor com capacidade superior a 50 toneladas de aço). Encontram-se estudos sobre a utilização do tampão cerâmico flutuante, provenientes de usinas de perfis (distribuidor de menor capacidade) e em condições operacionais bastante diferentes das de Tubarão. Por isso, dentro deste contexto, definiu-se não efetuar comparações que poderiam conduzir a análises não consistentes. Deixa-se, portanto, uma abertura para comparações futuras, a partir da implantação deste sistema em plantas que guardem similaridade com Tubarão.

\section{CONCLUSÃO}

A importância dos resultados obtidos com a implantação do tampão cerâmico flutuante possui um significado que extrapola o ganho econômico obtido, em particular para Tubarão, ao abrir o leque de utilização da fibra cerâmica diretamente em contato com o aço líquido, algo ainda pouco explorado. Os rigores da metodologia empregada bem como as análises aprofundadas dos resultados transmitem confiabilidade no emprego deste mecanismo em usinas de planos com distribuidores de maior capacidade.

* Contribuição técnica ao 450 Seminário de Aciaria - Internacional, 25 a 28 de maio de 2014, 
Acredita-se que dentro dos limites estabelecidos previamente todos os objetivos foram alcançados e os resultados permitiram uma implantação segura, sem restrições. Ressalta-se, porém, que o campo de estudos ainda possui um vasto território a ser explorado e por isso, espera-se brevemente o aparecimento de novas aplicações da fibra cerâmica como artefato de trabalho diretamente em contato com o aço líquido.

\section{Agradecimentos}

Os autores agradecem a todos que contribuíram direta e indiretamente na elaboração deste trabalho, em especial às equipes de Controle de Qualidade, Manutenção Eletromecânica e Refratária.

\section{REFERÊNCIAS}

1 Morais AA. Estudo Fenomenológico do Mecanismo de Obstrução do Fluxo de aço do Distribuidor para o Molde no Início do Lingotamento Contínuo de Placas [dissertação de mestrado]. Ouro Preto: Programa de Pós Graduação em Engenharia de Materiais, Universidade Federal de Ouro Preto; 2006. p.155-7.

2 Callister WD, Rethwisch DG. Ciência e engenharia de materiais: uma introdução. São Paulo: LTC Editora; 2002. p.589.

3 Duff ES. Fluid flow aspects of solidification modeling: simulation of low pressure die casting [tese de doutorado]. Brisbane: Department of Mining \& Metallurgical Engineering, University of Queensland; 1999. p.507-17.

4 Garcia A. Solidificação dos Metais [apostila de Curso]. Campinas: Faculdade de Engenharia Mecânica, Unicamp; 1980. p.858-66.

5 Kurz W, Fisher DJ. Fundamentals of solidification. $3^{\mathrm{a}}$ ed. Switzerland: Trans. Tech. Publications; 1992. p.199-201.

6 Lanik. Produtos, filtração de aço [acesso em 13 jun. 2008]. Disponível em: http://www.lanik.eu/filtrace-oceli/.

7 Werkema C. Criando a cultura Seis Sigma. Nova Lima: Werkema Editora; 2004. v.1, p.156-215.

8 Thomas B. Computational tools for analysis of fluid flow in metal casting processes. Huntington: Special Metals Corporation; 2003: 895-912.

* Contribuição técnica ao 45 Seminário de Aciaria - Internacional, 25 a 28 de maio de 2014, Porto Alegre, RS, Brasil. 